\title{
Crystallization and Preliminary X-Ray Crystallographic Studies of Rattus norvegicus Visfatin/PBEF/Nampt in Complex with an FK866-Based Inhibitor
}

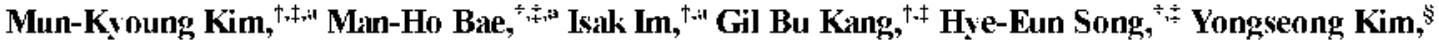 \\ Jang-Soo Chun, ${ }^{\dagger, t}$ Yong-Chul Kim, ${ }^{\dagger}$ and Soo Hyun Eom ${ }^{\dagger+.4 *}$

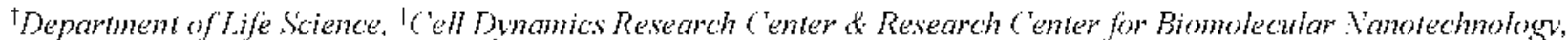 \\ Guangin Instinte of Science and Technologv, Guangin 500-7 I2. Norea "E-mail comiagistackr \\ Separtment of Chemistry, Kitungnam Lnivensitw, Hasan 631-701. Norea \\ Received Jamuary 28, 2009. 1ccepted February 23, 2009
}

Key Words: Crystallization. FK866. Nicolinamide phosphoribosyllans[erase (Namp1). Pre-B-cell colony-cnlancing factor (PBEF). Visfatin

Nicotinamide adenine dinucleotide $\left(\mathrm{NAD}^{+}\right)$plays a pivotal role in numerous biochemical and biological processes. Not only does it participate as a coen $y$ me during catalysis of redox reactions. it also series as a substrate in sereral biochemical reactions. including mono- and poly-ADP-ribosylation. protein deacetylation and ADP-ribose cyclization.

Malignant tumor cells show a higher than normal rate of $\mathrm{NAD}^{-}$tumover duc to increased ADP-ribosylation, "3 In these cells, expression of visfatin Ipre-B-cell colony-enhancing factor (PBEF)/nicotinamide phosphoribosyltransferase (Nampt)]. which is the rate-limiting enstme in the salvage pathway for $\mathrm{NAD}^{+}$synthesis. is upregulated so as to maintain adcquaie levels of $\mathrm{NAD}^{+}$. 5 Conscquently. visfatin is an attractive target for anticancer theraps: ${ }^{6 ?}$ Indeed. FK866, a small potent inllibitor of visfatin activity reduces $\mathrm{NAD}^{+}$ levels and induces apoptosis of tumor cells. A phase I clinical trial of FK 866 has already been successfully completed. ${ }^{9}$ and a phase II trial of its efficacy against several forms of human cancer is currently ongoing.

The cry stal siniclure of visfatin las becn solyed. with and without bound substrate, product and FK866. (it-1 $2^{\text {The }}$ structure of the visfatin-FK866 complex reveals how the inhibitor interacts with the enzyme's active site residues. Moreover. comparison of the structures of the visfatin-FK 866 and visfatin-micotinamide mononuclcotide (NMN) complexes shows how the pyridyl ring of FK866 is positioned at the nicolinamide ring of $\mathrm{NMN}$. Given that the ribose ring and phosphate group of NMN make good contacts wilh the active site residues of visfatin. we endeavored to design a larger
Table 1. Datá collection statistics

\begin{tabular}{|c|c|}
\hline & Visfatin-[S(001 Complex \\
\hline X-Itạ source & PAL $+A$ \\
\hline Wavelength $(\Lambda)$ & 1.0000 \\
\hline Space group & $P 2_{I} 2_{2} 2_{I}$ \\
\hline Unit cell dimensions $(\tilde{\Lambda})$ & $a=8.3 .3, b=107.4, c^{\prime}=120.2$ \\
\hline Resolution $(\AA)$ & $50-3.0(3.05-3.00)$ \\
\hline Observed rellections & 165.450 \\
\hline unique reflections & 22,256 \\
\hline Completeness $(\%)$ & $99.7(100)$ \\
\hline$R_{\text {: } 3 \mathrm{~m}}{ }^{*}(\%)$ & $14.0(33.4)$ \\
\hline $\mathrm{I} / \sigma(\mathrm{I})$ & $24.4(8.3)$ \\
\hline
\end{tabular}

FK866 derivative that would establish hydrogen bond interactions with residues in the NMN binding site. Toward that goal. we designed several hydrophilic moiclics that we added to FK866 to manipulate its phammacokinetic properties. Ultimately. we designed and synthesized ISO0 I, which las an additional ribose ring on the FK866 py ridyl ring

We found that erystals of visfatin in complex with ISOOI belong to the $P 2,2,2$, space group and have the unit-cell dimensions $a=83.3, b=107.4 . c=120.2 \mathrm{~A}, \alpha=\beta=\gamma=90^{\circ}$. Assuming one dimeric visfatin molecule is contained in an asymmetric uni1. the Matthews coefficient was calculated to be $2.41 \mathrm{~A}^{3} / \mathrm{Da}$ : the estimated solvent content was thus<smiles>CCCCCCCCCNC(=O)/C=C/c1cccnc1</smiles>

FK866

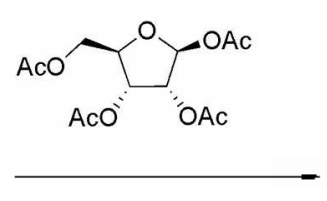

1. TMSOTf, MeCN, it, $1 \mathrm{~h}$

2. $\mathrm{MeOH}, 30 \mathrm{~min}$

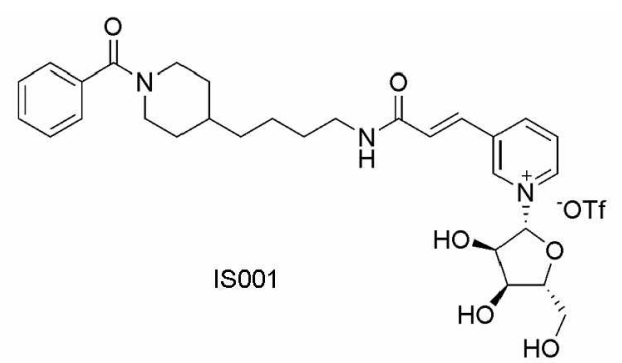

Scheme 1. Ruaction scheme for sunthesis of ISOO l.

"Ihesw authors have equally contributed to this work. 


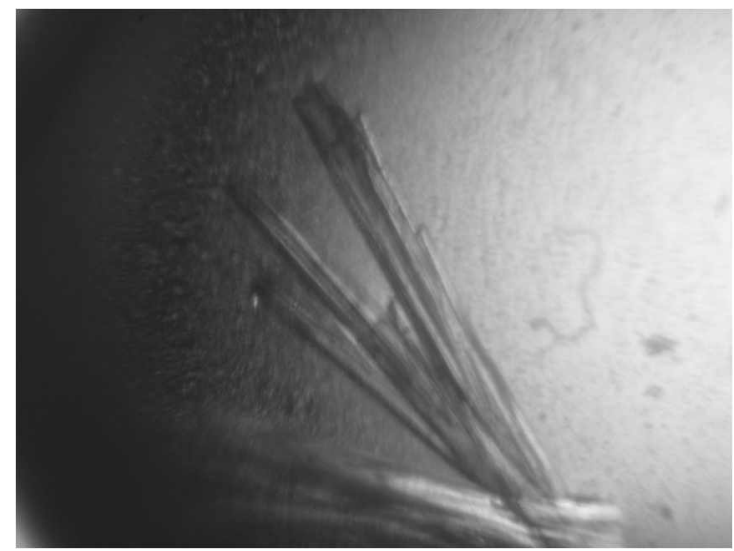

Figure 1. Crystals of visfatin-ISO01 complex. Visfatin-ISO0 l complex was crystallized using the hanging drop vapor diffusion method at $294 \mathrm{~K}$. Crvstals of the complex were made by mixing $\mathrm{I} \mu \mathrm{L}$ of protein solution and the same volunne of reservoir solution containing $0.2 \mathrm{M} \mathrm{MgCl}_{2}, 16 \%(\mathrm{w} / \mathrm{v}) \mathrm{PEG} 3330$ and $0.1 \mathrm{M}$ Hepes$\mathrm{NaOH}(\mathrm{pH} 7.5)$.

$48.9 \%,{ }^{14}$ which is typical for protein crystals. Initial molecular replacement calculations were carried out with MOLREP ${ }^{15}$ using search models based on the structure of Rattus nonegicus visfatin (PDB code 2G95). At present. model building and refinements are ongoing. The statistics for data collection are summarized in Table 1.

\section{Experimental Section}

Protein expression and purification. Recombinant rat visfatin fused with a hexahistidine tag was expressed in Escherichia coli BL2l(DE3) as described previously. ${ }^{9}$ For purification, the soluble protein was first applied to a nickel-agarose affinity chromatography column, after which the protein was eluted with buffer containing $50 \mathrm{mM}$ sodium phosphate ( $\mathrm{pH} 8.0$ ). $300 \mathrm{mM} \mathrm{NaCl}$ and $300 \mathrm{mM}$ imidazole. The eluate was then concentrated by ultrafiltration using an YM30 membrane (Amicon), and TEV protease was added to remove the hexahistidine tag. The partially purified visfatin was then added to a Superdex 200 column (GE-AmershamPharnacia) equilibrated with buffer containing $20 \mathrm{mM}$ Hepes$\mathrm{NaOH}(\mathrm{pH} 7.5)$ and $150 \mathrm{mM} \mathrm{NaCl}$. and fractions containing the recombinant protein were pooled and concentrated to 15 $\mathrm{mg} / \mathrm{mL}$

Chemical synthesis of the modified inhibitor IS001. We synthesized IS00 I as summarized in Scheme 1 . To a stirred solution of $\beta$-D-ribofuranose $1.2,3$,-t-tetraacetate (16.2 $\mathrm{mg}$. $0.051 \mathrm{~mol}$ ) and FK866 (20 mg. $0.05 \mathrm{l} \mathrm{mol})$ in dry acetonitrile $(2 \mathrm{~mL})$. we added TMSOTf ( $73 \mu \mathrm{L} .0 .41 \mathrm{~mol})$ dropwise at room temperature and then stirred the mixture for an additional
$1 \mathrm{~h}$ at the same temperature. Methanol $(1 \mathrm{~nL})$ was then added to the mixture and stirred for $30 \mathrm{~min}$ after which the solvent was evaporated under vacuum. and the residue was chromatographed on activated charcoal (eluted with $\mathrm{H}_{2} \mathrm{O}$ to $100 \% \mathrm{MeOH}$ ). After removing the solvent. the product was precipitated with ethyl acetate (12.7 $\mathrm{mg}, 18 \%$ ).

Crystallization and data collection. Crystallization trials were carried out in a 24-well plate using the hanging-drop vapor diffusion method. Crystals of rat visfatin in complex with IS00I were grown at $294 \mathrm{~K}$ under $0.1 \mathrm{M}$ Hepes- $\mathrm{NaOH}$ (pH 7.5). $0.2 \mathrm{M} \mathrm{MgCl}_{2} .16 \%$ (w/v) polyetlylene glycol 3350 (Figure 1). For cryogenic experiments. a suitable cryoprotectant was deternined to be paraton oil. A complete data set was collected at $100 \mathrm{~K}$ at BL-4A of the Pohang Accelerator Laboratory. Korea. Data sets were indexed and processed using the HKL2000 package. ${ }^{16}$

Aclnowledgments. We thank Drs. Heung-Soo Lee. KyungHwa Kim. Kyung Jin Kim. and Yeon-Gil Kim of BL-4A at the Polang Accelerator Laboratory. Pohang, Korea, for their kind support during data collection. This work was supported by a grant of the Korea Healthcare Technology R\&D Project. Ministry for Health. Welfare and Family Affairs, Republic of Korea (A062442).

\section{Refelences}

1. Ziegler, M. Em: J. Biochem. 2000, 267, 1550 .

2. Schreiber, V: Dantzer, F.; Ame, J. C. de Murcia, G. Nat Rev. ifol. Cell. Biol. 2006, 7,517.

3. Burkle, A. FEBS J. 2005, 272,4576

4. Hufton, S. E.: Moerkerk, P. T.; Brandwilk, R.: de Brume, A. P.; Arends, J. W.: Hoogenboom. H. R. FEBS Lett. 1999, $463,77$.

5. Van Beijnum, J. R.; Moerkerk, P. T:; Gerbers, A. J.; De Brume, A. P.: Arends, J. W.: Hoogenboom. H. R.; Hufton. S. E. Int. $J$. Cancer 2002, 101, 118

6. Rongvauly. A.: Shea, R. T.; Mulls, M. H.: Gigot, D.: Urbain. I.: Leo, O.; Andris, F. Eum J. lmmunol. 2002, $32,3225$.

7. Wosikowski, K.; Mattern, K.; Schemainda, I.; Hasmant, M.; Rattel, B.: Loser, R. K. Cancer Res. 2002, 62, 1057

8. Hasmann. M.: Schemainda. I. Cancer Res. 2003. 63. 7436.

9. Holen, K.; Saltz, L. B.; Hollywood, E.; Burk, K.; Hauske, A. R. Invest. New Drugs 2008, 26, 45.

10. Wang, T.; Zhang, X.; Bheda, P.; Revollo, I. R.; Imai, S.; Wolberger. C. Kat. Stmict. Mol. Biol. 2006. 13.661

11. Khan, J. A.: Tá, X.; Tong, L. Nat. Struct. Mol. Biol. 2006, 13, 582

12. Kim, M. K. Lee, T. H,; Kim, H.; Park, S. T.; Kim, S. H.; Kang, G B.: Lee, Y. S.: Kim. I. B.: Kim. K. K.: Suh. S. W.: Eom, S. H. J. Mol. Biol. 2006, 362,66 .

13. Choi, S.: Han, J; Park, S.; Ham, S. W. Bull Koreon Chem. Soc. $2008,29,1659$.

14. Matthews, B. W. J. Mol. Biol. 1968, 33.491

15. Vagin, A.: Teplyakov, A. tcta Cnst. D 2000, 56, 1622

16. Otwinowski, Z.; Minor, W. Methods Enzmmol 1997, 276, 307 